\title{
Pola Kemitraan dan Pendapatan Usaha Tani Tomat Beef di Serenity Farm
}

\section{Partnership and Income of Tomato Beef Businesses in Serenity Farm}

\author{
Nikhen Saraswati ${ }^{1 *}$, Ktut Murniati ${ }^{1}$, dan Adia Nugraha ${ }^{1}$ \\ ${ }^{1)}$ Jurusan Agribisnis/ Universitas Lampung \\ E-mail: nikhensaraswati19@gmail.com
}

\begin{abstract}
This research aims to analyze (1) the pattern of tomato beef farming partnership; (2) the cost structure; (3) income of beef tomato farming; and (4) the contribution of tomato beef farming income to the household income of tomato beef farmers. This research was conducted at Serenity Farm located in Cibodas Village, Lembang District, West Bandung Regency. The determination of the location was done intentionally (purposive). The research method used was the census method. Data collection supporting the research was conducted in March 2020. The types of data collected in this study included primary and secondary data, which were collected through questionnaires. Data analysis methods used were (1) partnership patterns were analyzed using descriptive analysis methods; (2) the cost structure was analyzed by dividing each cost component by the total cost to see the largest percentage of costs; (3) income was analyzed by reducing the total revenue with the total cost; (4) contribution of tomato beef farming income was analyzed by dividing the income of tomato beef farming with the overall household income. The conclusions obtained were (1) the pattern of a partnership between Serenity Farm and beef tomato farmers using the plasma-core pattern, in which Serenity Farm acts as the core and beef tomato farmers act as plasma; (2) the cost structure of the beef tomato farming in the first growing season consists of a fixed cost with a percentage of $9.21 \%$ and a variable cost with a percentage of $90.79 \%$, while in the second growing season the fixed cost has a percentage of $8.92 \%$ and the variable cost has a percentage of $91.08 \%$; (3) the income of beef tomato farming in the first growing season amounted to Rp 20,821,875 and in the second growing season amounted to $R p 20,891,319.44$ with a value of $R / C>1$; (4) The contribution of tomato beef farming income to the household income of farmers is $59.46 \%$ (Rp 41,713,194.44/year).
\end{abstract}

Keywords: beef tomatoes, cost structure, income, partnership patterns.

Disubmit : 21 Juni 2021 Diterima: 8 Oktober 2021, Disetujui : 29 Oktober 2021

\section{PENDAHULUAN}

Indonesia memiliki kekayaan alam yang melimpah dan berada pada posisi yang strategis, hal ini menyebabkan Indonesia menjadi negara agraris di mana sebagian penduduknya mempunyai mata pencaharian di bidang pertanian atau bercocok tanam. Melimpahnya kekayaan alam di Indonesia membuat pertanian menjadi salah satu pekerjaan yang dilakukan oleh penduduk Indonesia. Menurut Badan Pusat Statistik (2018) mencatat ada 30,64\% atau sekitar 33,487 juta penduduk Indonesia bekerja pada sektor 
Saraswati : Pola Kemitraan dan Pendapatan Usaha Tani ........

pertanian. Indonesia sebagai negara agraris menghasilkan berbagai jenis tanaman komoditas ekspor, diantaranya padi, jagung, kedelai, berbagai jenis sayuran, berbagai jenis cabai, ubi dan singkong. Selain itu, Indonesia dikenal dengan hasil perkebunan, diantaranya karet, kelapa, sawit, tembakau, kapas, kopi dan tebu. Namun saat ini, masih banyak sekali petani yang hidup dalam garis kemiskinan dan satu penyebabnya yaitu belum adanya kebijakan pemerintah yang membuat petani terlepas dari garis kemiskinan.

Saat ini, banyak petani yang tergabung dalam sebuah kelompok tani. Pada dasarnya, kelompok tani merupakan organisasi non formal di perdesaan yang ditumbuh kembangkan dari petani, oleh petani dan untuk petani serta memiliki fungsi sebagai kelas belajar, wahana kerjasama serta dan unit produksi. Pemerintah juga memiliki banyak program bagi kelompok tani yang bertujuan untuk meningkatkan kesejahteraan anggota taninya dan membebaskan petani dari garis kemiskinan (Nuryanti dan Swastika, 2016) Kabupaten Bandung Barat memiliki kelompok tani yang berjumlah 110 kelompok dan beberapa diantaranya terdapat di Kecamatan Lembang. Salah satu dari kelompok tani di Kecamatan Lembang yaitu Kelompok Tani Macakal. Kelompok Tani Macakal bermitra dan membangun kerjasama antara petani dengan berbagai pihak yang terkait, baik pihak akademis maupun pihak perbankan.

Serenity Farm merupakan salah satu divisi yang terdapat di Kelompok Tani Macakal. Serenity Farm dapat disebut sebagai perusahaan packing house skala menengah yang memasok berbagai jenis sayur ke beberapa tempat di Kota Bandung. Serenity Farm memiliki 44 mitra tani yang menjadi pemasok berbagai jenis sayuran yang kemudian akan dipasarkan oleh Serenity Farm. Komoditas unggulan yang paling diminati oleh konsumen Serenity Farm yaitu komoditas tomat beef. Tingginya biaya yang diperlukan untuk berusaha tani tomat beef menyebabkan tidak banyaknya mitra tani yang berminat untuk membudidayakan tomat beef karena adanya keterbatasan modal, sedangkan Serenity Farm harus menjaga ketersediaan tomat beef. Menyiasati hal tersebut, Serenity Farm memberikan pinjaman modal bagi mitra taninya. Mitra tani yang diberikan pinjaman modal tersebut hanya boleh menjual hasil produknya ke Serenity Farm dan kemudian dapat membayarkan pinjaman yang telah dilakukan secara bertahap selama 2 tahun dan dibayarkan saat tomat beef sudah panen. Serenity Farm dan petani tomat beef menjalin hubungan yang saling menguntungkan bagi kedua belah pihak sebagai mitra yang terikat kontrak.

Struktur biaya dalam usaha tani tomat beef perlu dianalisis untuk melihat apakah penerimaan yang dihasilkan lebih besar daripada biaya yang telah dikeluarkan. Pendapatan merupakan hal yang penting dalam berusaha tani, karena usaha tani dilakukan untuk mendapatkan keuntungan (profit). Pendapatan usaha tani tomat beef merupakan selisih dari penerimaan yang diterima oleh mitra tani. Pendapatan rumah tangga adalah pendapatan yang bersumber dari kegiatan usaha tani (on farm), kegiatan diluar usaha tani namun masih berhubungan dengan pertanian (off farm) dan kegiatan yang tidak berhubungan dengan pertanian (non farm). Kegiatan usaha tani tomat beef secara langsung memberikan kontribusi terhadap pendapatan rumah tangga. Berdasarkan uraian pada latar belakang maka perlu dilakukannya penelitian mengenai pola kemitraan usaha tani tomat beef, struktur biaya usaha tani tomat beef, pendapatan usaha tani tomat beef, kontribusi pendapatan terhadap pendapatan rumah tangga petani tomat beef di Serenity Farm.

\section{METODE PENELITIAN}

Penelitian ini termasuk penelitian deskriptif kuantitatif yang dilakukan pada bulan Maret 2020 di Serenity Farm. Penentuan lokasi secara sengaja (purposive) (Yolandika, Nurmalina and Suharno, 2017) dengan pertimbangan bahwa saat ini Kelompok Tani Macakal merupakan kelompok tani yang memiliki banyak prestasi dan salah satu divisinya yaitu Serenity Farm yang memproduksi tomat beef sejak akhir 2016. Responden dalam penelitian ini adalah mitra tani Serenity Farm baik yang berusaha tani pada komoditas tomat beef. Responden yang diwawancari berjumlah 9 orang yang seluruhnya merupakan mitra tani dari Serenity Farm yang dipilih melalui metode sensus dimana responden yang dipilih merupakan seluruh mitra tani dari Serenity Farm yang berusaha tani tomat beef. Pengambilan sampel tersebut diharapkan dapat 
menggambarkan bagaimana perbedaan pendapatan rumah tangga dari mitra tani dari sebelum dan setelah berusaha tani tomat beef.

Metode analisis tujuan pertama mengenai analisis pola kemitraan menggunakan analisis deskriptif, tujuan ke dua mengenai struktur biaya di analisis dengan melihat komponen biaya dalam usaha tani tomat beef, tujuan ke tiga mengenai pendapatan usaha tani di analisis dengan mengurangkan total penerimaan dengan total biaya, dan tujuan ke empat mengenai kontribusi pendapatan usaha tani tomat beef di analisis dengan membagi pendapatan usaha tani tomat beef dengan pendapatan rumah tangga secara keseluruhan. Penelitian ini menggunakan data primer dan sekunder. Data primer didapatkan melalui wawancara dengan pengurus Serenity Farm dan responden utamanya yaitu seluruh mitra tani yang berusaha tani tomat beef. Data sekunder merupakan data yang diperoleh dari laporan-laporan, studi literatur, publikasi, Badan Pusat Statistika (BPS) dan pustaka-pustaka lain yang berhubungan dengan penelitian ini. Rumus untuk menghitung total biaya yaitu:

$$
\mathrm{TC}=\mathrm{TFC}+\mathrm{TVC}
$$

Keterangan:

TC : Total biaya produksi

TFC : Total biaya tetap

TVC : Total biaya variabel

Persentase dari setiap struktur biaya dapat dihitung dengan rumus:

$\mathrm{P}=\frac{\mathrm{NTFC} \text { atau NTVC }}{\mathrm{NTC}} \times 100 \%$

Keterangan:

$\mathrm{P} \quad$ : Nilai dari struktur biaya produksi (\%)

NTFC : Nilai dari tiap komponen biaya tetap (Rp)

NTVC : Nilai dari tiap komponen biaya variabel (Rp)

NTC : Nilai dari total biaya produksi (Rp)

Pendapatan diperoleh dengan menghitung selisish antara penerimaan dengan total biaya produksi yang dikeluarkan. Rumus yang digunakan untuk menghitung pendapatan usaha tani tomat beef yaitu :

$$
\pi=\mathrm{TR}-\mathrm{TC}
$$

Keterangan:

$\pi \quad$ : Pendapatan usaha tani tomat beef

$T R$ : Total penerimaan (total revenue)

TC : Total biaya (total cost)

Rumus yang digunakan untuk menghitung Revenue Cost Ratio $(R / C)$ yaitu rumus menurut (Soekartawi, 2002):

$$
\frac{\mathrm{R}}{\mathrm{C}}=\frac{\mathrm{TR}}{\mathrm{TC}}
$$

Keterangan:

$T R$ : Total penerimaan (total revenue)

TC : Total biaya (total cost)

Terdapat tiga kriteria, yaitu $\mathrm{R} / \mathrm{C}=1$, maka usaha tani tomat beef yang diusahakan berada dalam titik impas, $\mathrm{R} / \mathrm{C}<1$, maka usaha tani tomat beef tidak menguntungkan, dan $\mathrm{R} / \mathrm{C}>1$, maka usaha tani tomat beef menguntungkan. Pendapatan rumah tangga petani sendiri berasal dari tiga sumber, yaitu pendapatan rumah tangga dari kegiatan usaha tani yang disebut dengan on farm, kegiatan diluar usaha tani tetapi masih berhubungan dengan pertanian yang disebut dengan off farm dan kegiatan lain diluar pertanian yang disebut dengan non farm. Mengukur tingkat pendapatan rumah tangga digunakan rumus (Widodo, 1990): 
Saraswati : Pola Kemitraan dan Pendapatan Usaha Tani ........

$\mathrm{Yrt}=\mathrm{Y}_{1}+\mathrm{Y}_{2}+\mathrm{Y}_{3}$

Keterangan:

Yrt : Pendapatan rumah tangga petani

$\mathrm{Y}_{1} \quad$ : Pendapatan on farm

$\mathrm{Y}_{2} \quad$ : Pendapatan off farm

$\mathrm{Y}_{3} \quad$ : Pendapatan non farm

Kontribusi pendapatan usaha tani tomat beef terhadap pendapatan rumah tangga dapat dihitung dengan rumus:

Kontribusi Pendapatan Usahatani $=\frac{\text { Pendapatan Usahatani }}{\text { Pendapatan Rumah Tangga }} \times 100 \%$

\section{HASIL DAN PEMBAHASAN}

\section{Karakteristik Responden}

Karakteristik responden pada penelitian ini meliputi umur, tingkat pendidikan, pengalaman berusaha tani, jumlah tanggungan keluarga, luas lahan, dan status kepemilikan lahan. Petani responden tergolong umur produktif yang berkisar antara $30-40$ tahun $(77,78 \%)$. Umur dari petani tomat beef memengaruhi hasil usaha tani tomat beef yang dilakukan, karena umur memengaruhi aktifitas dan produktivitas kerja seseorang (Mantra, 2004). Tingkat pendidikan petani tomat beef sebagian besar menyelesaikan pendidikan akhir hingga dibangku SMA (66,67\%). Pengalaman berusaha tani berkisar antara 4-16 tahun $(66,67 \%)$. Tingkat pengalaman usaha tani yang berbeda menyebabkan berbedanya pola pikir petani dalam menerapkan inovasi pada kegiatan berusaha tani selaras dengan pernyataan (Maramba, 2018) yang menyatakan bahwa dalam kegiatan berusaha tani, pengalaman merupakan modal penting yang akan menentukan keberhasilan usaha yang dilakukan. Mayoritas mitra tani memiliki jumlah tanggungan sebanyak 3 orang (55,55\%). Mayoritas mitra tani Serenity Farm memiliki luas lahan total antara $750 \mathrm{~m}^{2}-1000 \mathrm{~m}^{2}(55,56 \%)$ dengan luas lahan yang digunakan untuk usaha tani tomat beef berkisar antara $250 \mathrm{~m}^{2}-500 \mathrm{~m}^{2}$. Mayoritas mitra tani memiliki luas lahan tomat beef dengan status kepemilikan adalah milik sendiri sebesar $250 \mathrm{~m}^{2}(55,56 \%)$, luas lahan usaha tani dapat mempengaruhi produksi, didukung oleh penelitian (Ambarita dan Kartika, 2015) yang menyatakan bahwa luas lahan usaha tani berpengaruh terhadap produksi.

\section{Pola Kemitraan}

Kemitraan yang dilakukan oleh Serenity Farm dengan petani tomat beef menggunakan pola intiplasma yang merupakan hubungan kemitraan antara usaha kecil dengan usaha menengah atau usaha besar. Serenity Farm bertindak sebagai inti yang menyediakan naungan tomat beef, sarana produksi tomat beef, melakukan bimbingan teknis, manajemen, menampung serta memasarkan tomat beef, sedangkan petani bertindak sebagai plasma yang bertugas memenuhi kebutuhan Serenity Farm sesuai dengan kesepakatan yang telah disepakati. Hubungan kemitraan inti-plasma antara Serenity Farm sebagai pemberi bimbingan teknis produksi dan penyedia sarana produksi kepada mitra taninya yang mengusahakan tomat beef yang menjadi plasmanya, kemitraan tersebut meliputi; penyedia sarana produksi, melakukan bimbingan teknis dan manajemen, serta menampung dan memasarkan produk. Hubungan kemitraan inti plasma antara petani dan perusahaan agribisnis dilakukan untuk memberikan keuntungan kepada dua belah pihak. Hasil penelitian ini didukung oleh penelitian (Alam dan Hermawan, 2017) yang menyatakan bahwa pola hubungan yang dijalin antara petani kecil dengan CV. Asa Agro Corporation adalah pola kemitraan inti plasma dan faktor-faktor yang mempengaruhi keberhasilan kemitraan ini, seperti komunikasi, kerjasama,keprcayaan dan komitmen terhadap kemitraan.

\section{Pelaksanaan Kemitraan Usaha Tani Tomat Beef di Serenity Farm}

Tomat beef merupakan produk unggulan dari Sereity Farm, sehingga Serenity Farm perlu menjaga ketersediaan dari tomat beef. Tomat beef sendiri merupakan komoditas baru yang belum pernah diusahakan oleh mitra tani Serenity Farm sebelumnya. Usaha tani tomat beef juga memerlukan biaya yang cukup tinggi Volume 5 Nomor 2,Oktober Tahun 2021 | 119 
sehingga tidak banyak petani yang mau mengusahakan komoditas tomat beef karena keterbatasan modal. Petani tomat beef sebagai mitra dari Serenity Farm diberikan pinjaman modal berupa sarana produksi dan bangunan naungan. Kemitraan petani tomat beef dan Serenity Farm memiliki pola inti plasma. Serenity Farm berperan sebagai inti yang menyediakan bangunan naungan, sarana produksi tomat beef, melakukan bimbingan teknis, manajemen, menampung serta memasarkan tomat beef, sedangkan petani bertindak sebagai plasma yang bertugas memproduksi tomat beef dan hasilnya dijual kepada Serenity Farm sesuai dengan kesepakatan yang telah disepakati. Hasil penelitian ini sejalan dengan penelitian (Kurnianto, Subekti dan Nurjayanti, 2019) yang menyatakan bahwa pada pelaksanaan kemitraan antara peternak ayam broiler dengan perusahaan, petani berperan sebagai plasama yang bertugas untuk melakukan peternakan ayam broiler, sedangkan perusahaan bertindak sebagai inti yang menyediakan biaya produksi, memberikan bimbingan teknis, dan lain sebagainya.

\section{Pengadaan Sarana Produksi Usaha Tani Tomat Beef oleh Serenity Farm}

Sarana produksi untuk usaha tani tomat beef disediakan oleh Serenity Farm dalam bentuk pinjaman. Sarana produksi tersebut berupa bangunan naungan, benih, pupuk dan pestisida. Pinjaman tersebut dapat dibayarkan dalam jangka waktu 2 tahun dan jumlah angsurannya merupakan kesepakatan dari petani tomat beef dan Serenity Farm. Petani tomat beef dapat mulai mengangsur pinjaman tersebut saat tomat beef sudah panen. Secara keseluruhan, pinjaman modal bagi petani tomat beef pada lahan seluas $250 \mathrm{~m}^{2}$ dapat dilihat pada Tabel 1.

Tabel 1. Sarana produksi dari Serenity Farm

\begin{tabular}{ll}
\hline Jenis Sarana Produksi & Biaya (Rp) \\
\hline Naungan+pengolahan lahan+pengajiran & 5.000 .000 \\
Bibit @ Rp 4.500/pohon & 2.250 .000 \\
Pupuk (AB Mix+NPK+kandang) & 1.110 .000 \\
Pestisida (Per-Paket) & 1.200 .000 \\
\hline Jumlah & 9.560 .000 \\
\hline
\end{tabular}

Sumber: Data primer diolah, 2020

\section{Proses Budidaya Usaha Tani Tomat Beef}

Kegiatan pada proses budidaya usaha tani tomat beef dilakukan oleh petani tomat beef, baik menggunakan tenaga kerja dalam keluarga maupun tenaga kerja luar keluarga. Kegiatan-kegiatan proses budidaya usaha tani tomat beef meliputi:

\section{Pembuatan naungan, pengolahan lahan dan pengajiran}

Kegiatan pembuatan naungan, pengolahan lahan dan pengajiran dilakukan oleh tenaga kerja yang berasal dari Serenity Farm. Kegiatan ini memerlukan waktu selama 4 hari dan menggunakan 3 orang tenaga kerja.

\section{Penanaman}

Kegiatan penanaman benih hanya memerlukan waktu 1 hari dengan jumlah tenaga kerja sebanyak 1-2 orang. Bibit yang ditanam merupakan bibit berumur 2 minggu dengan tinggi sekitar $20 \mathrm{~cm}$.

\section{Pemeliharaan}

Kegiatan dalam pemeliharan tanaman tomat beef meliputi, penyiangan, pemupukan, dan pengendalian HPT. Penyiangan dilakukan dengan mencabuti gulma yang tumbuh di sekitar tanaman dan menyirami tanaman tomat beef sebanyak dua kali sehari saat pagi dan sore hari.

\section{Pemupukan}


Saraswati : Pola Kemitraan dan Pendapatan Usaha Tani ........

Kegiatan pemupukan dimulai saat tanaman berumur 7 hari hingga usia tanaman habis atau tidak dapat berproduksi lagi. Pemupukan dilakukan dua kali dalam seminggu. Pupuk yang digunakan yaitu pupuk kandang, pupuk AB mix dan pupuk NPK. Rata-rata penggunaan pupuk kandang yaitu 186,67 kg, pupuk AB mix 43,89 kg, dan pupuk NPK $56 \mathrm{~kg}$.

\section{Pengendalian HPT}

Kegiatan pengendalian HPT dilakukan bergantung dengan ada tidaknya indikasi terhadap hama atau penyakit yang menyerang tanaman. Pengendalian HPT dilakukan setiap5 hingga 7 hari sekali. Pestisida yang digunakan merupak pestisida paket terdiri dari alika amistar, skor ridomil gold dan lannate $25 \mathrm{WP}$.

\section{Pemanenan}

Kegiatan pemanenan tomat beef dapat mulai dilakukan pada usia tanaman 90 hari atau 3 bulan. Pemanenan tomat beef dilakukan 2 hingga 3 hari sekali dengan memanen tomat beef yang udah berwarna kuning kemerahan, atau yang belum terlalu matang.

\section{Saluran Pemasaran Usaha Tani Tomat Beef}

Tomat beef yang telah diproduksi oleh petani tomat beef seluruhnya dijual ke Serenity Farm. Salah satu kesepakatan pada kemitraan antara petani tomat beef dan Serenity Farm, yaitu petani tomat beef hanya diperbolehkan menjual hasil produksi usaha tani tomat beef ke Serenity Farm dengan harga yang telah ditetapkan. Harga yang diberikan sesuai dengan kualitas dari tomat beef. Kualitas A seharga Rp 11.000, kualitas B seharga Rp 10.000, kualitas C seharga Rp 6.000 dan kualitas CN seharga Rp 1.500. Kesepakatan lain antara petani tomat beef dan Serenity Farm yaitu, memberikan bimbingan teknis dan manajemen kepada petani tomat beef mengenai budidaya tomat beef. Komoditas tomat beef merupakan komoditas baru yang diusahakan oleh mitra tani, sehingga mitra tani belum terbiasa. Pihak Serenity Farm sudah menentukan jumlah bibit, penggunaan pupuk dan penggunaan pestisida selama usaha tani berlangsung. Serenity Farm memberikan bimbingan teknis mengenai budidaya tomat beef.

Serenity Farm juga mengharuskan mitra taninya untuk disiplin dalam manajemen pembukuan usaha tani tomat beef, sehingga saat mitra tani mengambil sarana produksi di Serenity Farm harus membawa buku khusus yang digunakan untuk pencatatan sarana produksi yang diambil, begitupun saat mitra tani membawa hasil produksi tomat beef ke Serenity Farm sehingga pencatatan selama usaha tani berlangsung jelas. Kemitraan antara petani tomat beef dan Serenity Farm memberikan keuntungan bagi kedua belah pihak. Petani tomat beef mendapatkan keuntungan dengan disediakannya pinjaman modal berupa sarana produksi, diberikan bimbingan teknis dan manajemen mengenai budidaya tomat beef dan sudah jelasnya tempat penjualan bagi hasil produksi usaha tani tomat beef, sedangkan Serenity Farm mendapatkan keuntungan dengan terjaganya ketersediaan komoditas tomat beef.

Hasil penelitian ini sejalan dengan (Pasaribu, Hasanuddin, dan Nurmayasari, 2013) yang menunjukan bahwa pola kemitraan pada usaha tani kelapa sawit antara petani kelapa sawit dan PT Perkebunan Nusantara VII adalah pola kemitraan inti plasma. PT Perkebunan Nusantara VII bertindak sebagai pemberi pinjaman modal berupa bibit kelapa sawit dan memberikan bimbingan teknis mengenai penanaman, pemeliharaan hingga pemanenan kelapa sawit yang baik.

\section{Struktur Biaya Usaha Tani Tomat Beef}

Salah satu komponen dasar yang penting dalam melakukan kegiatan usaha tani yaitu biaya. Penggunaan biaya yang efisien akan berpengaruh terhadap penerimaan dan pendapatan petani. Peningkatan efisiensi biaya dapat ditingkatkan dengan mengetahui struktur biaya yang dikeluarkan selama usaha tani dijalankan. Struktur biaya merupakan persentase dari komponen-komponen penyusun biaya total dalam usaha tani. Struktur biaya usaha tani tomat beef dapat dilihat pada Gambar 1. 


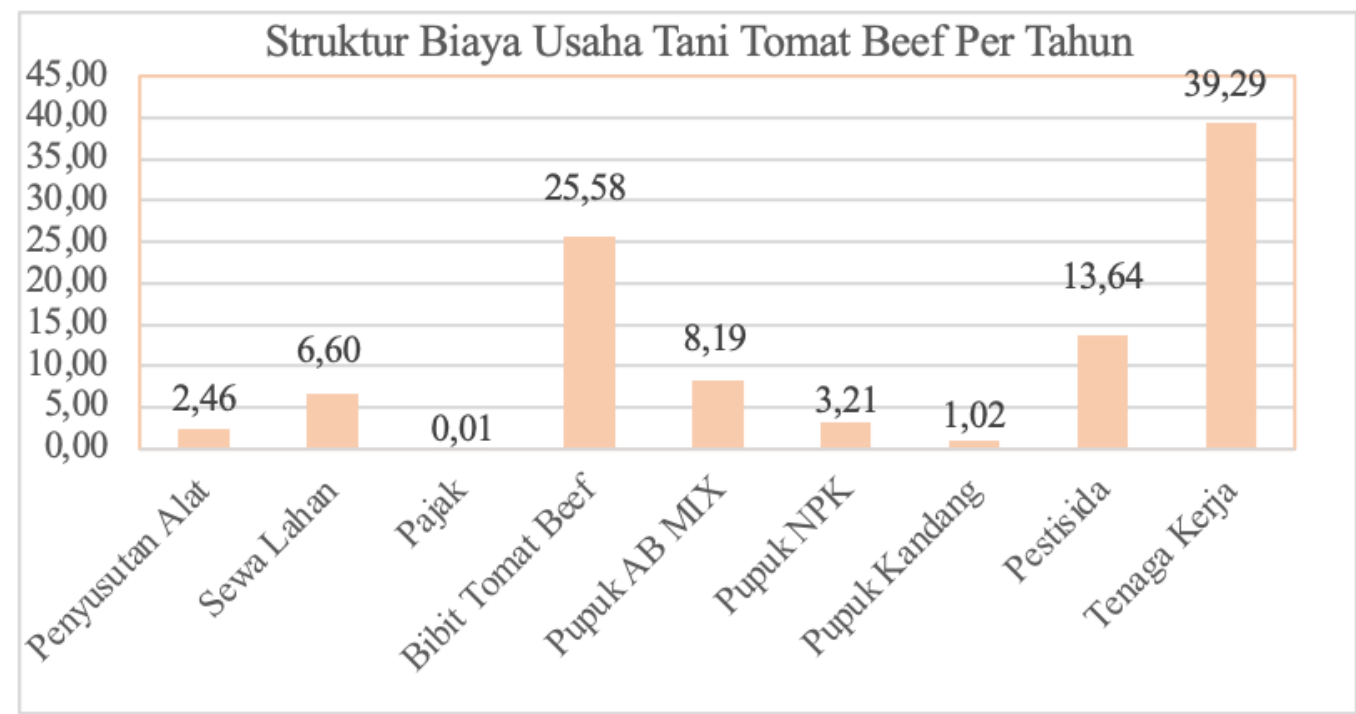

Gambar 1. Komponen-komponen biaya usaha tani tomat beef per tahun Sumber: Data primer diolah, 2020

Berdasarkan Gambar 1, persentase biaya tetap pada usaha tani tomat beef per tahunnya yaitu sebesar $9,07 \%$ dan biaya variabel dengan persentase sebesar $90,93 \%$. Biaya yang paling tinggi yaitu biaya tenaga kerja, biaya bibit tomat beef dan biaya pestisida dengan persentase masing-masing sebesar 39,29\%, 25,58\% dan 13,64. Hasil penelitian ini sejalan dengan (Saputra, 2019) yang menunjukan bahwa biaya variabel yang digunakan pada usaha tani mentimun lebih besar dibandingkan biaya tetap pada usaha tani mentimun. Persentase biaya variabel pada usaha tani mentimun sebesar $84,03 \%$ dan persentase biaya tetap sebesar $15,97 \%$. Hal ini disebabkan karena biaya variabel akan berubah seiring adanya perubahan produk yang dihasilkan, sedangkan biaya tetap akan dikeluarkan meskipun tidak menghasilkan produk.

\section{Pendapatan Usaha Tani Tomat Beef}

Mitra tani Serenity Farm melakukan usaha tani tomat beef sebanyak dua musim tanam dalam satu tahun. Masing-masing musim memerlukan waktu kurang lebih empat bulan atau 120 hari. Penerimaan total serta pendapatan yang diterima mitra tani berbeda setiap musimnya, bergantung dengan banyaknya produksi yang dihasilkan dalam satu musim. Berbeda dengan penerimaan dan pendapatan yang jumlahnya berbeda setiap musim, biaya yang dikeluarkan mitra tani pada setiap musim tanam tomat beef akan sama, hal tersebut disebebakan input yang digunakan mitra tani sudah ditentukan oleh pihak Serenity Farm dan mitra tani mengikuti aturan tersebut.

Pendapatan atas biaya tunai usaha tani tomat beef mitra tani Serenity Farm di musim tanam I dengan rata-rata lahan seluas $0,039 \mathrm{Ha}$ sebesar $\mathrm{Rp} 20.821 .875$. R/C atas biaya tunai sebesar 3,02 yang artinya pada setiap $\mathrm{Rp} 1,00$ biaya tunai yang mitra tani keluarkan dalam usaha tani tomat beef akan diperoleh penerimaan Rp 3,02. Nilai tersebut menunjukan bahwa usaha tani tomat beef layak diusahakan karena nilai R/C $>1$. Produktivitas yang tinggi dan harga jual yang pasti membuat keuntungan yang didapatkan oleh mitra tani Serenity Farm cukup tinggi. Pendapatan atas biaya tunai usaha tani tomat beef mitra tani Serenity Farm di musim tanam IIdengan rata-rata lahan seluas 0,039 Ha sebesar $\mathrm{Rp} 0.891 .319,44$. R/C atas biaya tunai sebesar 3,14 yang artinya pada setiap Rp 1,00 biaya tunai yang mitra tani keluarkan dalam usaha tani tomat beef akan diperoleh penerimaan $\mathrm{Rp} 3,14$. Nilai tersebut menunjukan bahwa usaha tani tomat beef menguntungkan karena nilai $\mathrm{R} / \mathrm{C}>1$.

Pendapatan atas biaya tunai mitra tani Serenity Farm pada usaha tani tomat beef pada musim tanam I dan musim tanam II mengalami perbedaan, dimana pendapatan petani tomat beef pada musim tanam II lebih besar dibandingkan musim tanam I. Perbedaan pendapatan usaha tani tomat beef pada musim tanam I dan musim tanam II sebesar Rp 69.444,44. Pendapatan atas biaya tunai usaha tani tomat beef selama satu tahun 
Saraswati : Pola Kemitraan dan Pendapatan Usaha Tani ........

dengan rata-rata lahan seluas 0,039 Ha sebesar Rp 41.713.194,44. R/C atas biaya tunai sebesar 3,08 yang artinya pada setiap $\mathrm{Rp}$ 1,00 biaya tunai yang mitra tani keluarkan dalam usaha tani tomat beef akan diperoleh penerimaan $\mathrm{Rp} \mathrm{3,08.} \mathrm{Nilai} \mathrm{tersebut} \mathrm{menunjukan} \mathrm{bahwa} \mathrm{usaha} \mathrm{tani} \mathrm{tomat} \mathrm{beef} \mathrm{menguntungkan} \mathrm{karena} \mathrm{nilai}$ $\mathrm{R} / \mathrm{C}>1$. Pendapatan usaha tani tomat beef tinggi disebabkan karena petani tomat beef menjalin kemitraan dengan Serenity Farm, sehingga ketersediaan sarana produksi dan harga tomat beef sudah terjamin. Selain itu, Serenity Farm juga menampung hasil produksi tomat beef sehingga petani tidak kesulitan mencari tempat untuk menjual hasil pertaniannya. Hasil penelitian ini sejalan dengan komoditas hortikultura lain yaitu sawi pada penelitian (Nubatonis, 2016) yang menunjukan bahwa usaha tani sawi memilki nilai R/C sebesar 3,27, artinya secara ekonomi usaha tani sawi menguntungkan sehingga layak untuk diusahakan dan dapat memberikan pendapatan sebesar Rp 7.500.000/musim tanam.

\section{Kontribusi Pendapatan Usaha Tani Tomat Beef Terhadap Pendapatan Rumah Tangga}

Pendapatan dapat dibedakan menjadi dua, yaitu pendapatan usaha tani dan pendapatan rumah tangga petani (Yolandika, Lestari and Situmorang, 2015). Pendapatan rumah tangga dari kegiatan usaha tani disebut dengan on farm, kegiatan diluar usaha tani tetapi masih berhubungan dengan pertanian disebut dengan off farm dan kegiatan lain diluar pertanian disebut dengan non farm (Gustiana, 2017). Mitra tani Serenity Farm tidak menggunakan seluruh lahannya untuk melakukan usaha tani tomat beef. Lahan yang tidak digunakan untuk melakukan usaha tani tomat beef digunakan untuk berusaha tani komoditas lain. Komoditas yang dipilih diantaranya sawi, horenzo, tomat cherry, tomat lokal dan cabai hijau besar. Pendapatan mitra tani Serenity Farm dari usaha tani lain selain usaha tani tomat beef dapat dilihat pada Tabel 2.

Tabel 2. Usaha on farm selain tomat beef selama satu tahun

\begin{tabular}{lcrrrrr}
\hline $\begin{array}{c}\text { Usaha } \text { On Farm } \\
\text { Lain }\end{array}$ & $\begin{array}{c}\text { Jumlah } \\
(\text { Orang) }\end{array}$ & Harga (Rp) & \multicolumn{1}{c}{$\begin{array}{c}\text { Biaya } \\
(\mathrm{Rp})\end{array}$} & $\begin{array}{c}\text { Produksi } \\
(\mathrm{Kg})\end{array}$ & $\begin{array}{r}\text { Penerimaan } \\
(\mathrm{Rp})\end{array}$ & $\begin{array}{c}\text { Pendapatan } \\
(\mathrm{Rp})\end{array}$ \\
\hline Sawi & 2 & 8.000 & 19.000 .000 & 7.700 & 61.600 .000 & 42.600 .000 \\
Horenzo & 2 & 15.000 & 59.400 .000 & 6.600 & 99.000 .000 & 39.600 .000 \\
Cabai Hijau Besar & 2 & 8.000 & 53.700 .000 & 11.500 & 92.000 .000 & 38.300 .000 \\
Tomat Lokal & 1 & 7.000 & 10.000 .000 & 3.000 & 21.000 .000 & 11.000 .000 \\
Tomat Cherry & 2 & 12.000 & 37.500 .000 & 6.000 & 72.000 .000 & 34.500 .000 \\
\hline Jumlah & & & 179.600 .000 & 34.800 & 345.600 .000 & 166.000 .000 \\
\hline Rata-rata & & & $19.955 .555,56$ & $3.866,67$ & 38.400 .000 & 18.444 .444 \\
\hline
\end{tabular}

Sumber: Data primer diolah, 2020

Pendapatan di luar usaha tani (off farm) merupakan pendapatan yang dihasilkan oleh mitra tani setelah melakukan pekerjaan di luar usaha tani yang dilakukan namun masih berhubungan dengan sektor pertanian. Pendapatan pertahun sebagai pedagang sayuran sebesar Rp 36.000.000 dan sebagai peternak ayam sebesar Rp 48.000.000 sehingga pendapatan rata-rata mitra tani pada usaha off farm sebesar Rp 9.333.333,33. Pendapatan luar pertanian (non farm) merupakan pendapatan yang dihasilkan oleh mitra tani dari kegiatan yang tidak berhubungan dengan pertanian. Mitra tani yang memiliki pekerjaan lain di luar pertanian (non farm) hanya satu orang saja, yaitu sebagai guru honorer. Pendapatan pertahun sebagai guru honorer yaitu sebesar Rp 6.000.000 sehingga pendapatan rata-rata mitra tani pada usaha non farm sebesar Rp 666.666,67.

Pendapatan rumah tangga merupakan pendapatan total suatu rumah tangga yang berasal dari kegiatan on farm, off farm dan non farm. Pada suatu rumah tangga, kepala keluarga adalah seseorang yang wajib bekerja untuk memenuhi kebutuhan rumah tangganya, namun pendapatan rumah tangga juga dihitung dari pendapatan yang berasal dari anggota keluarga yang lainnya. Pendapatan rumah tangga diperoleh dengan cara menjumlahkan pendapatan keluarga dari usaha tani tomat beef, pendapatan usaha tani komoditas lain, 
pendapatan usaha tani diluar kegiatan budidaya, serta pendapatan yang berasal dari kegiatan diluar pertanian. Struktur pendapatan rumah tangga mitra tani Serenity Farm dapat dilihat pada Tabel 3.

Tabel 3. Struktur pendapatan rumah tangga mitra tani Serenity Farm

\begin{tabular}{lrr}
\hline \multicolumn{3}{c}{ Rata-Rata Pendapatan RT Mitra Tani Serenity Farm } \\
\hline Jenis Pendapatan & Pendapatan Diterima $(\mathrm{Rp})$ & Persentase $(\%)$ \\
\hline On Farm Tomat Beef & $41.713 .194,44$ & 59,46 \\
On Farm Lain & 18444444,44 & 26,29 \\
Off Farm & 9333333,33 & 13,30 \\
Non Farm & 6666666,67 & 0,95 \\
\hline Jumlah & $70.157 .638,89$ & 100 \\
\hline
\end{tabular}

Sumber: Data primer diolah, 2020

Tabel 3 menjelaskan bahwa pendapatan tomat beef memiliki kontribusi terhadap pendapatan rumah tangga sebesar 59,46\% (Rp 41.713.194,44) per tahunnya. Kondisi ini menunjukan bahwa pendapatan usaha tani tomat beef merupakan pendapatan utama bagi rumah tangga mitra tani, hal ini disebabkan karena harga tomat beef yang diterima terjamin dan tidak berfluktuasi karena mitra tani bermitra dengan Serenity Farm. Tidak adanya fluktuasi harga tomat beef yang diterima petani ini menyebabkan pendapatan tomat beef menjadi pendapatan yang paling tinggi. Hasil penelitian ini sejalan dengan penelitian (Sundari and Utami, 2012) yang menunjukan bahwa usaha tani ubi jalar memiliki kontribusi sebesar 50,59\% (Rp 5.231.000) terhadap pendapatan rumah tangga petani artinya, pendapatan usaha tani ubi jalar merupakan pendapatan utama bagi petani di Desa Ukirsari.

\section{KESIMPULAN DAN SARAN}

\section{Kesimpulan}

Pola kemitraan antara Serenity Farm dengan petani tomat beef menggunakan pola inti-plasma, dimana Serenity Farm bertindak sebagai inti dan petani tomat beef bertindak sebagai plasma.Struktur biaya pada usaha tani tomat beef pada musim tanam I terdiri dari biaya tetap dengan persentase sebesar $9,21 \%$ dan biaya variabel dengan persentase sebesar 90,79\%, sedangkan pada musim tanam II biaya tetap memiliki persentase $8,92 \%$ dan biaya variabel memiliki persentase $91,08 \%$. Pendapatan usaha tani tomat beef pada musim tanam I sebesar Rp 20.821.875 dan pada musim tanam II sebesar Rp 20.891.319,44. Keduanya memiliki nilai $\mathrm{R} / \mathrm{C}>1$ sehingga usaha tani tomat beef menguntungkan. Kontribusi pendapatan usaha tani tomat beef terhadap pendapatan rumah tangga petani yaitu sebesar 59,46\% (Rp 41.713.194,44/tahun), sehingga usaha tani tomat beef menjadi pendapatan utama pada pendapatan rumah tangga petani tomat beef.

\section{Saran}

Saran yang dapat diberikan hasil penelitian ini, yaitu bagi Serenity Farm agar memperluas lahan untuk usaha tani tomat beef karena hasil produksi usaha tani tomat beef stabil sehingga Serenity Farm dapat selalu menjaga ketersediaan komoditas tomat beef, bagi petani lain agar tumbuh keinginan untuk berusaha tani tomat beef karena usaha tani tomat beef menguntungkan sehingga layak untuk diusahakan.

\section{DAFTAR PUSTAKA}

Alam, A. S. and Hermawan, H. (2017) 'Faktor-faktor yang mempengaruhi hubungan kemitraan antara petani budidaya jamur tiram dengan cv. asa agro corporation', AGROSCIENCE (AGSCI), 7(1), pp. 214-219.

Ambarita, J. P. and Kartika, I. N. (2015) 'Pengaruh luas lahan, penggunaan pestisida, tenaga kerja, pupuk terhadap produksi kopi di Kecamatan Pekutatan Kabupaten Jembrana’, E-Jurnal Ekonomi Pembangunan Universitas Udayana, 4(7), p. 44553. 
Saraswati : Pola Kemitraan dan Pendapatan Usaha Tani

Badan Pusat Statistik (2018) Analisis Mobilitas Tenaga Kerja Hasil Survei Angkatan Kerja Nasional 2018.

Gustiana, E. (2017) Analisis Pendapatan dan Distribusi Pendapatan Usahatani Tebu Rakyat di Kecamatan Bunga Mayang, Kabupaten Lampung Utara. Universitas Lampung.

Kurnianto, A., Subekti, E. and Nurjayanti, E. D. (2019) 'Analisis usaha peternakan ayam broiler pola kemitraan Inti-Plasma (Studi kasus peternak plasma PT. Bilabong di Kecamatan Limpung Kabupaten Batang)', Mediagro, 14(2).

Mantra, I. B. (2004) Filsafat penelitian \& metode penelitian sosial. Pustaka Pelajar.

Maramba, U. (2018) 'Pengaruh Karakteristik Terhadap Pendapatan Petani Jagung di Kabupaten Sumba Timur (Studi Kasus: Desa Kiritana, Kecamatan Kambera, Kabupaten Sumba Timur)', Jurnal Ekonomi Pertanian dan Agribisnis, 2(2), pp. 94-101.

Nubatonis, A. (2016) 'Analisis Pendapatan Usahatani Sawi di Desa Humusu Oekolo Kecamatan Insana Utara Kabupaten Timor Tengah Utara', Agrimor, 1(01), pp. 1-2.

Nuryanti, S. and Swastika, D. K. S. (2016) 'Peran kelompok tani dalam penerapan teknologi pertanian', in Forum penelitian agro ekonomi, pp. 115-128.

Pasaribu, A. I., Hasanuddin, T. and Nurmayasari, I. (2013) 'Pola kemitraan dan pendapatan usahatani kelapa sawit: Kasus kemitraan usahatani kelapa sawit antara PT Perkebunan Nusantara VII unit usaha Bekri dengan petani mitra di Desa Tanjung Jaya, Kecamatan Bangun Rejo, Kabupaten Lampung Tengah', Jurnal IlmuIlmu Agribisnis, 1(4), pp. 358-367.

SAPUTRA, B. (2019) 'ANALISIS STRUKTUR BIAYA, PENDAPATAN USAHATANI DAN PEMASARAN MENTIMUN DI KECAMATAN WAY SULAN KABUPATEN LAMPUNG SELATAN’.

Soekartawi (1995) Analisis Usahatani. Universitas Indonesia.

Sundari, H. A. and Utami, D. P. (2012) 'Kontribusi Usahatani Ubi Jalar (Ipomoea batatas L.) Terhadap Pendapatan Rumah Tangga Petani di Desa Ukirsari Kecamatan Grabag Kabupaten Purworejo', Surya Agritama: Jurnal Ilmu Pertanian dan Peternakan, 1(2).

Widodo, H. S. T. (1990) Indikator ekonomi: dasar perhitungan perekonomian Indonesia. Penerbit Kanisius. Yolandika, C., Lestari, D. A. H. and Situmorang, S. (2015) 'Keberhasilan Koperasi Unit Desa (KUD) Mina Jaya Kota Bandar Lampung Berdasarkan Pendekatan Tripartite', Jurnal Ilmu-Ilmu Agribisnis, 3(4), pp. 385392.

Yolandika, C., Nurmalina, R. and Suharno, S. (2017) ‘Analisis Nilai Tambah Brokoli Kemasan Cv. Yan'S Fruits and Vegetable Di Kecamatan Lembang Bandung Barat', Journal of Food System \& Agribusiness, 1(1), pp. 30-37. doi: 10.25181/jofsa.v1i1.84. 